\title{
Comparison of sevoflurane/fentanyl and isoflurane/fentanyl during elective coro- nary artery bypass surgery
}

Purpose: Due to the progressive aging of the surgical population, the proportion of patients with coronary artery disease $(C A D)$ is likely to increase. The effects of the new inhalational anaesthetic sevoflurane must be determined in patients with known CAD.

Methods: This multicentre, randomized, open-label study compared the haemodynamic and cardiovascular effects of sevoflurane and isoflurane with fentanyl in 284 ASA physical status II-IV patients undergoing elective coronary artery bypass graft (CABG).

Results: Satisfactory records were available in 272 patients, 139 sevoflurane (Group S) and 133 isoflurane (Group I). There were no differences between groups for demographic

\section{Key word}

ANAESTHESIA: cardiac;

ANAESTHETICS, INTRAVENOUS: fentanyl;

ANAESTHETICS, VOLATILE: isoflurane, sevoflurane;

HEART: coronary artery disease; myocardial ischaemia;

MONITORING: blood pressure; haemodynamics; Holter

electrocardiography: pulse rate;

SURGERY: coronary artery bypass graft.

From the *Department of Anaesthesia, Montreal Heart Institute, Montreal, Quebec, Canada; †Inst. für

Anästhesiologie, Munich, Germany; $¥$ Department of Anaesthesia, Leicester, United Kingdom; §Department of Anesthesiology, Johns Hopkins University, Baltimore, MD USA; IDepartment of Anesthesia, St. Luke's Medical Center, Milwaukee, WI, USA; IDepartment of Anesthesiology, Durham, NC, USA.

This study was supported by a grant from Abbott Laboratories, Ltd, Chicago, IL.

Address correspondence to: Dr. Norman Searle, Department of Anaesthesia, Montreal Heart Institute, 5000

Belanger Street, Montreal, Quebec H1T 1C8 Canada. Phone: (514) 376-3330. Fax: (514) 376-8784. Accepted for publication 11th May, 1996.
Norman R. Searle MD, * Raymond J. Martineau MD, * Peter Conzen MD, $\uparrow$ A. Al-Hasani MD, $\ddagger$ Lynette Mark MD, $\S$ Thomas Ebert MD,II Michael Muzi MD, $\mathbb{I}$ Lewis R. Hodgins MD, $\|$ and the Sevoflurane Venture Group data except that more patients in Group $S$ were taking preoperative beta-blockers $(P=0.03)$. The mean end-tidal $M A C$ and MAC.hr requirements between groups were not different (Group $S$ received $0.63 \pm 0.02 \mathrm{MAC}$ and $1.00 \pm 0.05 \mathrm{MAC} \cdot \mathrm{hr}$ while Group I received $0.58 \pm 0.02 \mathrm{MAC}$ and $0.92 \pm 0.05$ $M A C \cdot h r P=N S)$. The preCPB use of intravenous fentanyl was not different between groups. There was a similar decrease in haemodynamic variables in both groups after induction that persisted throughout the preCPB period. The incidence of preCPB myocardial ischaemia, adverse haemodynamic events and use of vasoactive drugs did not differ between groups. The incidence of postoperative myocardial infarction was $2.2 \%$ for Group $S$ and Group $I$ was $4.5 \%$ ( $P=$ NS). There were five postoperative deaths, one of which was attributed to a cardiac cause (Group I).

Conclusion: In patients undergoing elective CABG with low risk factors, either sevoflurane or isoflurane, combined with fentanyl, provided an acceptable preCPB haemodynamic profile and cardiac outcomes.

Objectif: A cause du vieillissement de la population chirurgicale, une augmentation proportionnelle de patients souffrant de maladie coronarienne athérosclérotique (MCAS) est à prévoir. Les effets des nouveaux agents volatils anesthésiques. tels le desflurane et le sévoflurane, doivent être déterminés chez les patients ayant une MCAS.

Méthode: Cette étude ouverte, multicentrique, randomisée a comparé les effets hémodynamiques et cardio-vasculaires du sévoflurane et de l'isoflurane en association avec du fentanyl chez 284 patients ASA II-IV subissant une chirurgie de revascularisation myocardique (CABG).

Résultats: Un total de 272 patients évaluables ont servi à l'analyse dont 139 patients sévoflurane (Groupe S) et 133 patients isoflurane (Groupe I), Il n'y avait pas de différence démographique entre les groupes à l'exception d'une utilisation préopératoire plus grande de bêta-bloqueurs dans le Groupe $S(P=0.03)$. La moyenne du MAC de fin d'expiration et le MAC.hr pour chacun des groupes étaient similaires 
(Groupe S a reçu $0.63 \pm 0.02$ MAC et $1.00 \pm 0.05$ MAC.hr tandis que le Groupe I a reçu $0.58 \pm 0.02$ MAC et $0.92 \pm 0.05$ $M A C \cdot h r ; P=N S)$. L'utilisation du fentanyl préCEC était similaire. A la suite de l'induction et durant le maintien de l'anesthésie préCEC, une réduction similaire des paramètres hémodynamiques fut enregistrée. L'incidence d'ischémie myocardique préCEC, d'événements hémodynamiques adverses et l'utilisation d'agents vasoactifs étaient similaires. $L$ 'incidence d'infarctus du myocarde pour le Groupe $S$ est de $2.2 \%$ et $4.5 \%$ pour le Groupe I $(P=N S)$. Il y eut cinq décès postopératoires, dont un était attribué à une cause cardiaque (Groupe I).

Conclusion: Pour des patients à bas risque subissant une $C A B G$, le sévoflurane et l'isoflurane, en association au fentanyl, procurent un profil hémodynamique préCEC et des résultats cardiaques acceptables.

Because of the physiological burdens imposed on the heart by surgery and anaesthesia, the perioperative period may be one of instability for patients with coronary artery disease (CAD): Current anaesthetic practice devotes considerable attention to preservation of myocardial function and avoidance of myocardial ischaemia. In order to meet these objectives, anaesthetic agents must be able to achieve predictable control of systemic arterial pressure; maintain stable cardiac rhythm and not induce myocardial ischaemia during all phases of anaesthesia. For these reasons, the safety of anaesthetic drugs in patients with CAD has been the focus of intense scrutiny in recent years. ${ }^{1-7}$ The effects of newer inhalational anaesthetic drugs, desflurane, 89 and sevoflurane, must also be determined in patients with known CAD before gaining widespread acceptance.

In healthy patients, the cardiovascular effects of sevoflurane are similar to those of other volatile anaesthetics. ${ }^{10-12}$ Compared with isoflurane, there may. be less tachycardia associated with sevoflurane. ${ }^{11}$ Like all presently available potent inhalational anaesthetics, it tends to depress cardiovascular function in a dosedependent manner via negative inotropic and peripheral vasodilatation. ${ }^{13,14}$ The ability of sevoflurane to induce coronary steal has not been demonstrated in experimental animal models. ${ }^{15-17}$

However, the haemodynamic effects of sevoflurane have not been documented in patients with CAD. This multicentre open-labelled study was undertaken to assess the cardiovascular effects of two inhalational anaesthetic agents, sevoflurane and isoflurane supplemented with fentanyl anaesthesia in patients undergoing elective coronary artery bypass graft (CABG) surgery. The primary endpoints were to assess the efficacy in maintaining haemodynamic stability, the haemodynamic adverse events, the incidence of pre-cardiopulmonary bypass myocardial ischaemia, volatile anaesthetic requirement and adverse cardiac events.

\section{Methods}

After obtaining Internal Review and Bioethics Committees approval and written informed consent, 284 patients, ASA physical status II-IV patients and New York Heart Association (NYHA) class I or II, scheduled to undergo elective coronary bypass graft surgery, were enrolled from 13 participating centres (see Appendix for list of participating institutions).

On the morning of surgery, patients were randomly allocated (1:1 in sealed envelope) to receive either sevoflurane (Group S) or isoflurane (Group I). Patients were between 18 and $80 \mathrm{yr}$ of age, and had documented ischaemic heart disease with $70 \%$ occlusion in one or more major coronary arteries, and/or $50 \%$ occlusion of the left main coronary artery. Patients with significant valvular heart disease, with a severely impaired left ventricular function (ejection fraction $<30 \%$ ) or with an uninterpretable ECG (left bundle branch block, wide QRS, Mobitz II or III atrioventricular block), were excluded. In addition, patients with any of the following were excluded: childbearing potential, known preexisting central nervous disease, drug or alcohol abuse.

The study sample size was computed to show a $15 \%$ reduction in myocardial ischaemia between the two volatile anaesthetic agents. Assuming an incidence of myocardial ischaemia pre-cardiopulmonary bypass (CPB) of $15 \%$ for isoflurane patients, the assumed sample size sufficient to detect such a difference between groups at the 0.05 (2-tailed) significance level with $80 \%$ power if such differences should exist is 140 patients per group.

\section{Monitoring}

On arrival in the operating room, under local anaesthesia, intravenous and radial artery canulae and a thermodilution pulmonary artery catheter were inserted. Electrocardiographic monitoring of lead II and $\mathrm{V}_{5}$ with continuous ST-segment analysis and trending was applied. Pulse oximetry, capnography and body (bladder and nasopharyngeal) temperature were monitored throughout surgery. End-tidal gases monitoring included both inspired and expired inhalational anaesthetic agents using an infrared anaesthetic gas analyzer (Datex Capnomac, Helsinki, Finland).

Anaesthetic technique and cardiopulmonary bypass Usual cardiac medications, including beta-adrenergic blocking agents, calcium channel blocking agents and nitrates, were continued up to, and included the morning 
of the surgery. All patients were premedicated with diazepam $\left(0.1-0.3 \mathrm{mg} \cdot \mathrm{kg}^{-1}\right)$ po and morphine $(0.1-0.2$ $\mathrm{mg} \cdot \mathrm{kg}^{-1}$ ) im 60-90 $\mathrm{min}$ before surgery.

Anaesthesia was induced with midazolam $(0.1-0.3$ $\left.\mathrm{mg} \cdot \mathrm{kg}^{-1}\right)$ and fentanyl $\left(5-15 \mu \mathrm{g} \cdot \mathrm{kg}^{-1}\right)$ while the patient breathed $100 \%$ oxygen. Upon loss of consciousness, study inhalational drug was introduced and titrated according to its haemodynamic effect. Tracheal intubation was facilitated with the use of vecuronium bromide $\left(0.1-0.2 \mathrm{mg} \cdot \mathrm{kg}^{-1}\right)$ and controlled ventilation was initiated to maintain end-tidal $\mathrm{CO}_{2}$ at $35-40 \mathrm{mmHg}$. An additional bolus of fentanyl (up to $10 \mu \mathrm{g} \cdot \mathrm{kg}^{-1}$ ) was allowed at sternotomy if the volatile anaesthetic could not control the surgical stress response. End-tidal concentrations of each anaesthetic vapor were kept less than 2.0 MAC equivalents, i.e., $4.1 \%$ for sevoflurane and $2.3 \%$ for isoflurane. Administration of the volatile anaesthetic agent was discontinued at the onset of CPB. After the start of $\mathrm{CPB}$, anaesthesia was maintained by administration of midazolam, fentanyl and vecuronium as clinically judged by each investigator.

During CPB, the degree of hypothermia, the type of oxygenator (membrane or bubble) and the technique for cardioplegic myocardial protection were not standardized and were according to the local preference of each site. Surgeons were asked to assess the quality of coronary anastomosis using a predefined qualitative scale as follows: poor, fair, good and excellent.

\section{Haemodynamic boundaries}

Maintenance of anaesthesia was primarily achieved with the inhalational study drug, titrated as required to keep blood pressure and heart rate within $\pm 20 \%$ of baseline ward measurements (average of three to five blood pressure measurements) throughout the prebypass period. Strict criteria and a protocol were followed to maintain haemodynamic parameters within predefined limits. Systolic blood pressure $>120 \%$ of baseline or $>160$ $\mathrm{mmHg}$, if not responsive to deepening of anaesthesia, was treated with sodium nitroprusside (SNP). Systolic blood pressure $<80 \%$ of baseline or $<90 \mathrm{mmHg}$, was corrected using intravenous fluids, decreasing anaesthetic concentrations and, if necessary, small boluses of ephedrine or phenylephrine were used at the discretion of the anaesthetist. Intravenous esmolol was used to maintain heart rate $<+20 \%$ of baseline or $<100 \mathrm{bpm}$ throughout the study period. Sinus bradycardia (heart rate $<50 \mathrm{bpm}$ ) was treated with atropine. Intravenous nitroglycerine was administered if myocardial ischaemia was detected by two-channel ST-segment analysis (1$\mathrm{mm}$ depression for >one minute or a 2-mm elevation for $>$ one minute) on the cardiac monitor in the absence of any haemodynamic change.

\section{Data collection}

Before surgery, patients had a complete medical history and physical examination. Complete blood count, coagulation profile, electrolytes, blood glucose, liver and renal function were determined preoperatively and daily for three days postoperatively. In addition, serum creatine kinase myocardial isoenzyme fraction (CK-MB) was determined at baseline, immediately after surgery and every eight hours for the next $72 \mathrm{hr}$. All blood samplings for CK-MB determination was assayed at a central laboratory centre (SciCor Inc., Indianapolis, IN). The creatine kinase-MB isoenzyme criterion for myocardial infarction (CK-MB MI) was defined by CK-MB $100 \mathrm{ng} \cdot \mathrm{ml}^{-1}$ at any time after surgery; or $\geq 70 \mathrm{ng} \cdot \mathrm{ml}^{-1}, 12 \mathrm{hr}$ after surgery; or $\geq 10 \mathrm{ng} \cdot \mathrm{ml}^{-1}, 24 \mathrm{hr}$ after surgery.

Twelve-lead ECGs were recorded at baseline preoperatively, postoperatively for three days and before hospital discharge. Two-lead Holter monitoring $\left(\mathrm{CC}_{5}\right.$ and $\mathrm{CM}_{5}$ ) was initiated the night before surgery and continued during surgery until CPB was started. The frequency response of the ECG and Holter monitors met the specifications of the American Heart Association for cut off limit of high $(80 \mathrm{~Hz})$ and low $(0.05 \mathrm{~Hz})$ frequencies and the effects of positional variations on ECG and calibration were ascertained. All ECG tracings and Holter tapes were analyzed by an independent cardiologist (Healthcare Services International, Redmond, WA) blinded to study drug and to the clinical evolution of the patient. Electrocardiographic changes consistent with myocardial ischaemia were defined as reversible ST-segment changes lasting at least one minute and involving a shift from baseline of either $1 \mathrm{~mm}$ of ST depression or $2 \mathrm{~mm}$ of ST elevation $60 \mathrm{msec}$ from the J point. The baseline ST-segment level was defined as the average ST segment over a stable period (at least 15 $\mathrm{min}$ ) preceding each episode of myocardial ischaemia. Similarly, electrocardiographic evidence of myocardial infarction (ECG-MI) was diagnosed when new $Q$ waves ( $\geq 40 \mathrm{msec}, 25 \%$ of $\mathrm{R}$ wave) appeared on a 12-lead ECG (based on the ECG interpretation made by the blinded cardiologist).

Haemodynamic measurements included systemic and pulmonary pressures, heart rate, central venous and pulmonary wedge pressures, and cardiac indices at baseline and at specified times throughout surgery. Study drug in $\mathrm{MAC} \cdot \mathrm{hr}$ requirements and anaesthetic adjuvant dosages were recorded for comparison between groups. Frequency, duration and severity of myocardial ischaemia episodes were compared. Finally, adverse major outcomes were classified as follows: cardiac death, MI and ventricular failure. Cardiac death was defined as mortality during hospitalization attributable to MI, dysrhyth- 
mia or heart failure related to a cardiac condition. Myocardial infarction was diagnosed using ECG and CK-MB criteria and heart failure was defined as a cardiac index $<2 \mathrm{~L} \cdot \mathrm{min}^{-1} \cdot \mathrm{m}^{-2}$ and requiring prolonged inotropic support with or without intraaortic balloon pump.

\section{Data analyses}

All results are presented as mean \pm standard error of the mean unless stated otherwise. Statistical analyses were performed using SAS (Statistical Analysis System Inc). Differences between groups were considered statistically significant when $P<0.05$. Descriptive statistics were used to summarize gender, race, age, height, and weight of patients by treatment groups. One-way analysis of variance (ANOVA) or repeated measurements ANOVA were used to compare continuous variables and Fisher's exact or Cochran-Mantel-Haenszel tests were used to compare categorical values as appropriate.

\section{Results}

A total of 284 patients were enrolled and randomized. Eleven randomized patients were not treated for different reasons such as surgery delayed, postponed or rescheduled. In one patient, administration of the study drug (sevoflurane) was discontinued after four minutes because the patient became haemodynamically unstable. This patient was not included in the analysis for efficacy parameters. For the 272 remaining patients, 139 patients received sevoflurane (Group S) and 133 patients received isoflurane (Group I).

Both groups were similar in height, weight, age, gender distribution, and ASA physical status (Table I). Distribution of patients was similar in regard to the following characteristics: Canadian Cardiovascular Society and NYHA functional classes, previous MI, previous CABG surgery, peripheral vascular disease and hypertension. Both groups had the same degree of coronary lesions in the left main (26\% vs $17 \%$ in Groups S and I respectively, $P=\mathrm{NS}$ ), and in each of the three major coronary branches. Preoperative medication history was comparable between groups except for a slightly greater proportion of patients on beta-blockers therapy (75\% vs $62 \%, P=0.03$ ) in the sevoflurane group (Table I).

Duration of surgery, CPB and aortic cross-clamp varied greatly between institutions $(P<0.001)$, but was similar in both groups (Table II). In the sevoflurane group, an average of 2.86 vessels (median $=3$ ) were grafted compared with 2.88 vessels (median $=3$ ) in the isoflurane group. No difference was observed between the two treatment groups for the overall quality of grafts, using the worst quality of grafts for each patient (Table II).
TABLE I Patient demographics, preoperative status and preoperative cardiac medication

\begin{tabular}{lccl}
\hline & $\begin{array}{c}\text { Sevoflurane } \\
(n=140)\end{array}$ & $\begin{array}{c}\text { Isoflurane } \\
(n=133)\end{array}$ & $P$ value \\
\hline Age (yr) & $60 \pm 8$ & $59 \pm 8$ & NS \\
Weight (Kg) & $80 \pm 14$ & $80 \pm 14$ & NS \\
Sex (M : F) & $117: 23$ & $115: 18$ & NS \\
ASA (II/III/IV) & $3 / 99 / 38$ & $5 / 97 / 31$ & NS \\
NYHA class (I/II) & $35 / 105$ & $36 / 97$ & NS \\
Hypertension & $75(54 \%)$ & $62(47 \%)$ & NS \\
Previous MI & $72(51 \%)$ & $57(43 \%)$ & NS \\
Peripheral vascular disease & $10(7 \%)$ & $18(14 \%)$ & NS \\
Redo-CABG & $7(5 \%)$ & $6(4.5 \%)$ & NS \\
Nitrates & $120(86 \%)$ & $108(81 \%)$ & NS \\
Beta-blockers & $105(75 \%)$ & $83(62 \%)$ & 0.03 \\
Calcium entry blockers & $83(59 \%)$ & $79(59 \%)$ & NS \\
\hline
\end{tabular}

$\mathrm{MI}=$ myocardial infarction. NYHA $=$ New York Heart Association NS $=$ not significant. Redo-CABG $=$ Redo-coronary artery bypass graft. Values are mean $\pm S D$.

TABLE II Duration of surgery, number and qualitative assessment of coronary anastomosis

\begin{tabular}{lccl}
\hline & $\begin{array}{c}\text { Sevoflurane } \\
(n=140)\end{array}$ & $\begin{array}{c}\text { Isoflurane } \\
(n=133)\end{array}$ & $P$ value \\
\hline Duration of surgery (min) & $230 \pm 5$ & $235 \pm 5$ & NS \\
Duration of CPB (min) & $93 \pm 3$ & $97 \pm 3$ & NS \\
Aortic cross-clamp (min) & $54 \pm 2$ & $58 \pm 2$ & NS \\
Patients $\leq 2$ grafts $(n)$ & 47 & 47 & NS \\
Patients $\geq 3$ grafts $(n)$ & 92 & 86 & NS \\
Quality of mammary grafts & & & \\
- Good/excellent $(n)$ & 135 & 138 & NS \\
- Poor/fair $(n)$ & 14 & 13 & \\
Quality of venous grafts & & & \\
- Good/excellent $(n)$ & 225 & 193 & 0.054 \\
- Poor/fair $(n)$ & 21 & 33 & \\
\hline
\end{tabular}

$\mathrm{CPB}=$ cardiopulmonary bypass. Values are mean $\pm \mathrm{SEM}$. NS $=$ not significant.

Drug requirements of sevoflurane and isoflurane during the study period between induction of anaesthesia and initiation of CPB are shown in Table III. No differences were observed between the two treatment groups for any of the anaesthetic concentrations. The interaction observed between investigator and treatment for the minimum concentrations of anaesthesia during induction to incision and incision to the onset of CPB was significant. The average concentration of anaesthesia expressed in MAC exposure was $0.63 \pm 0.02$ in the sevoflurane group and $0.58 \pm 0.02$ in the isoflurane group. The MAC $\cdot h r$ of anaesthesia was $1.00 \pm 0.05$ in the sevoflurane group and $0.92 \pm 0.05$ in the isoflurane group. In both groups, duration of drug administration, end-tidal concentrations (expressed in equipotent MAC units) and study drug requirements expressed in 
TABLE III Use of inhalational and intravenous anaesthetic drugs

\begin{tabular}{lcll}
\hline & $\begin{array}{l}\text { Sevoflurane } \\
(n=140)\end{array}$ & $\begin{array}{l}\text { Isoflurane } \\
(n=133)\end{array}$ & $P$ value \\
\hline Concentration (MAC units) & & & \\
- Before surgical incision & $0.32 \pm 0.02$ & $0.30 \pm 0.02$ & $\mathrm{NS}$ \\
- After surgical incision & $0.63 \pm 0.02$ & $0.58 \pm 0.02$ & $\mathrm{NS}$ \\
Duration of exposure $(\mathrm{min})$ & $110 \pm 4$ & $114 \pm 4$ & $\mathrm{NS}$ \\
Total exposure $(\mathrm{MAC} \cdot \mathrm{hr})$ & $1.00 \pm 0.05$ & $0.92 \pm 0.05$ & $\mathrm{NS}$ \\
Fentanyl at induction $\left(\mu \mathrm{g} \cdot \mathrm{kg}^{-1}\right)$ & $11.5 \pm 0.4$ & $11.1 \pm 0.3$ & $\mathrm{NS}$ \\
Total PreCPB fentanyl $\left(\mu \mathrm{g} \cdot \mathrm{kg}^{-1}\right)$ & $17.0 \pm 0.7$ & $16.7 \pm 0.7$ & $\mathrm{NS}$ \\
Number of patients $\mathrm{receiving}$ & & & \\
- Fentanyl $<10 \mu \mathrm{g} \cdot \mathrm{kg}^{-1}(n)$ & 32 & 35 & $\mathrm{NS}$ \\
- Fentanyl $>10<15 \mu \mathrm{gg} \cdot \mathrm{kg}^{-1}(n)$ & 33 & 26 & $\mathrm{NS}$ \\
- Fentanyl $=25 \mu \mathrm{g} \cdot \mathrm{kg}^{-1}(n)$ & 11 & 10 & $\mathrm{NS}$ \\
Midazolam at induction $(\mathrm{mg})$ & $8.4 \pm 0.3$ & $8.6 \pm 0.4$ & $\mathrm{NS}$ \\
\hline
\end{tabular}

$\mathrm{CPB}=$ cardiopulmonary bypass. Values are mean $\pm \mathrm{SEM}$. NS $=$ not significant.

Concentration and duration of administration are displayed in MAC units and hours respectively.

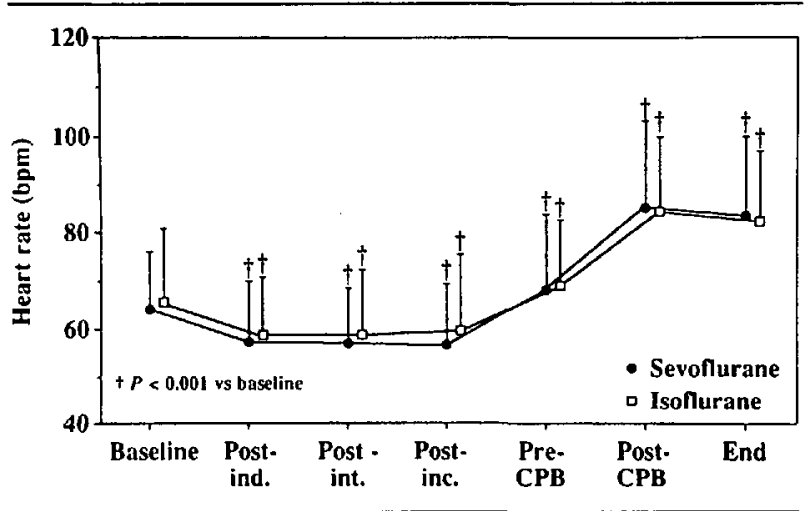

FIGURE 1 Mean perioperative heart rate for sevoflurane and isoflurane at baseline, postinduction (Postind), postintubation (Postint), postincision (Postinc), precardiopulmonary bypass (PreCPB), postcardiopulmonary bypass (PostCPB) and end of surgery (End).

MAC $\cdot$ hr were identical. Due to variations in duration of surgery between each center, there was a wide range of MAC exposure (0.53-1.93 MAC $\cdot \mathrm{hr} ; P<0.001$ for sevoflurane and $0.46-1.65 \mathrm{MAC} \cdot \mathrm{hr} ; P<0.001$ for isoflurane), but there was no difference between treatment groups within each centre. The use of supplemental intravenous fentanyl was similar in both groups.

The variation in haemodynamic variables during study drug administration are shown in Figures 1 to 3, and the incidence of haemodynamic adverse events and use of vasoactive drugs are shown in Tables IV and V. From induction to onset of CPB, there was a significant decrease in heart rate, systolic blood pressure and cardiac index compared to baseline values. Following CPB, cardiac index returned to baseline values, while heart

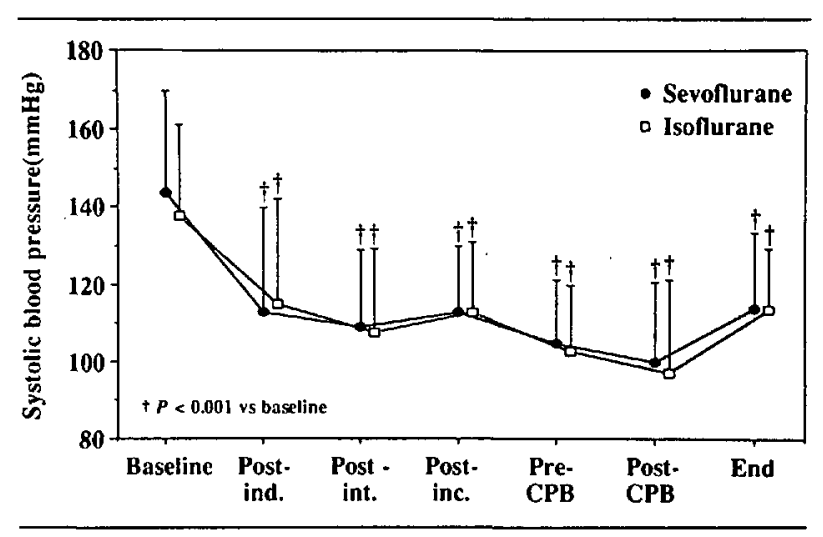

FIGURE 2 Mean perioperative systolic blood pressure for sevoflurane and isoflurane at baseline, postinduction (Postind), postintubation (Postint), postincision (Postinc), precardiopulmonary bypass (PreCPB), postcardiopulmonary bypass (PostCPB) and end of surgery (End).

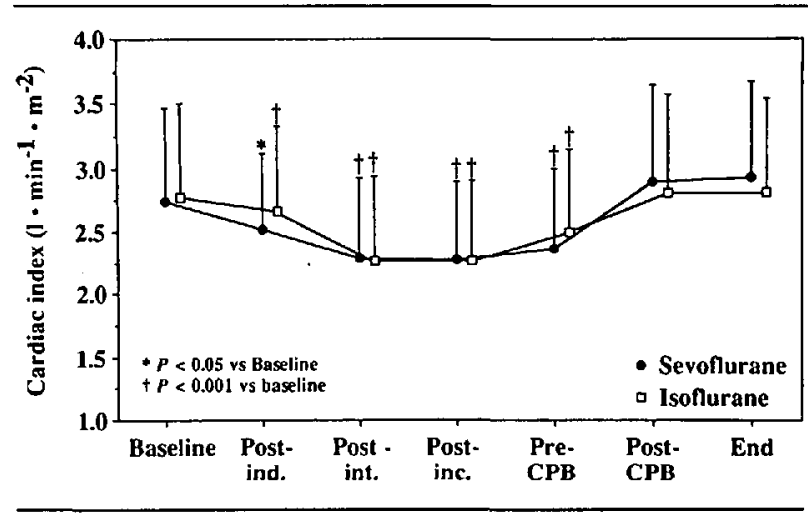

FIGURE 3 Mean perioperative cardiac index for sevoflurane and isoflurane at baseline, postinduction (Postind), postintubation (Postint), postincision (Postinc), precardiopulmonary bypass (PreCPB), postcardiopulmonary bypass (PostCPB) and end of surgery (End).

TABLE IV Summary of haemodynamic changes prior to cardiopulmonary bypass

\begin{tabular}{lccl}
\hline & $\begin{array}{c}\text { Sevoflurane } \\
(n=140)\end{array}$ & $\begin{array}{c}\text { Isoflurane } \\
(n=133)\end{array}$ & $P$ value \\
\hline Tachycardia & 4.3 & 2.3 & NS \\
Bradycardia & 13.6 & 12.7 & NS \\
Hypertension & 5 & 6 & NS \\
Hypotension & 34 & 36 & NS \\
\hline
\end{tabular}

Values are expressed in percent of population. NS = not significant.

rate increased to higher preCPB values and remained higher for the duration of the surgery. The systolic blood pressure remained lower post-CPB. However, no differences between Group $S$ and Group I were found in any of the haemodynamic variables. 
TABLE $V$ Use of adjunct vasoactive medication prior to cardiopulmonary bypass

\begin{tabular}{lccl}
\hline & $\begin{array}{c}\text { Sevoflurane } \\
(n=140)\end{array}$ & $\begin{array}{c}\text { Isoflurane } \\
(n=133)\end{array}$ & P value \\
\hline Atropine & 10.1 & 9 & NS \\
Calcium blockers & 2.9 & 4.5 & NS \\
Dopamine & 12.2 & 12 & NS \\
Ephedrine & 21.6 & 24.1 & NS \\
Esmolol/beta-blockers & 4.3 & 2.3 & NS \\
Phenylephrine & 20.9 & 22.6 & NS \\
Nitroglycerine & 13.7 & 15 & NS \\
Nitroprusside & 3.6 & 2.3 & NS \\
\hline
\end{tabular}

Values are expressed in percent of population. NS $=$ not significant.

Holter monitoring data were obtained in 235 patients before anaesthesia and during the study. The results are presented in Table VI. Holter data could not be analyzed in 37 patients: five due to technical malfunction, and 32 because of noninterpretable recordings. Myocardial ischaemia was detected in $29(12.3 \%)$ patients preoperatively and in $22(9.0 \%)$ patients from induction till initiation of CPB. Each study group had a similar number of patients showing intraoperative myocardial ischaemia: nine (7\%) in the sevoflurane group and 13 $(11 \%)$,in the isoflurane group $(P=\mathrm{NS})$. At onset of each myocardial ischaemia episode, heart rate was similar in both groups (68 \pm 4 and $73 \pm 4$ for sevoflurane and isoflurane respectively, $P=\mathrm{NS}$ ). The severity of myocardial ischaemia episode was $28.1 \pm 9.5 \mathrm{~mm} \cdot \mathrm{min}^{-1}$ for the isoflurane patient and $37.1 \pm 13.8 \mathrm{~mm} \cdot \mathrm{min}^{-1}$ for the sevoflurane patient $(P=\mathrm{NS})$. There were no difference in the ratio of patient on $\beta$-blocking drugs and the incidence of myocardial ischaemia.

Mortality and serious adverse cardiac outcomes (MI or heart failure) are shown in Table VII. Overall, five (1.8\%) patients died postoperatively, one of which was attributed to a cardiac cause (Group I). No statistical differences were found between groups in regard to any of these outcomes. The incidence of MI diagnosed by the CK-MB criteria and ECG criteria is shown in Table VII. Diagnosis of MI, having both ECG and CK-MB isoenzyme criteria, yielded a $2.2 \%$ incidence for Group $S$ while Group I had a $4.5 \%$ incidence $(P=N S)$. Using either myocardial infarction criteria showed an incidence of $19.4 \%$ for sevoflurane and a $15.8 \%$ for isoflurane $(P=\mathrm{NS})$. The overall $\mathrm{CK}-\mathrm{MB}$ profile in the first three postoperative days was similar in both groups, with a peak value during the first day of $39 \pm 43$ $\mathrm{ng} \cdot \mathrm{kg}^{-1}$ in the sevoflurane group and $38 \pm 47 \mathrm{ng} \cdot \mathrm{kg}^{-1}$ in the isoflurane group.

\section{Discussion}

Our results suggest that sevoflurane is very similar to isoflurane when used as either the primary or adjunct volatile anaesthetic agent for patients undergoing elective coronary artery surgery. Both sevoflurane and isoflurane were indistinguishable for their cardiovascular effects throughout the prebypass period. Following induction of anaesthesia, decreases in systolic blood pressure, heart rate, and cardiac index occurred and was identical in both groups. Thereafter, these variables remained stable following tracheal intubation, skin incision, sternotomy, and prior to onset of CPB except for a further decrease in cardiac index $(6 \%)$.

Using our predefined haemodynamic criteria, we recorded a $3.3 \%$ and $5.5 \%$ incidence of tachycardia and hypertension respectively. During maintenance of anaesthesia, supplemental doses of fentanyl were administered in order to blunt the sympathetic stress response. Only eight patients (3\%) did not respond to deepening of anaesthesia to control systemic hypertension and required the use of SNP, five in Group $S$ and three in Group I. Our results are in agreement with a recent study which demonstrated a lower incidence of hypertension associated with an opioid-volatile anaesthesia technique. ${ }^{18}$ In the latter study, all patients who became either hypertensive and/or tachycardic were better managed by deepening the anaesthetic level with either isoflurane or enflurane while, in the opioid group, supplemental sufentanil was ineffective in $25 \%$ of patients at induction-intubation and in $50 \%$ of patients during the remainder of the prebypass period.

The combined effect of premedication with a midazo$\mathrm{lam} / \mathrm{fentanyl} / \mathrm{vecuronium} /$ volatile induction and maintenance with a volatile agent and supplemental fentanyl is responsible for this low incidence of tachycardia/hypertension but may also have caused the $35 \%$ incidence of hypotension and $13 \%$ incidence of bradycardia (Table IV). These haemodynamic events were transient and were easily controlled with adjustments of volatile anaesthetic concentration and, if required, small doses of anticholinergic and intravenous fluids and/or vasopressors (Table V).

Volatile anaesthetic requirements between induction of anaesthesia and initiation of CPB were similar but varied among centres. This variation is explained by the amount of preCPB fentanyl used. As expected, an inverse relationship was seen between the volatile anaesthetic and fentanyl requirement. When the volatile agent served as the primary anaesthetic agent, the fentanyl requirement was low. For those centres, using the upper limit of fentanyl dosage, they recorded much lower MAC $\cdot$ hr requirement. Because of the close similarity in haemodynamic response and $\mathrm{MAC} \cdot \mathrm{hr}$ require- 
TABLE VI Summary of ischaemic events from continuous Holter monitoring

\begin{tabular}{|c|c|c|c|c|}
\hline \multirow[b]{2}{*}{ Agent } & \multicolumn{2}{|c|}{ Before surgery } & \multicolumn{2}{|c|}{ During surgery } \\
\hline & $\begin{array}{l}\text { Sevoflurane } \\
(n=121)\end{array}$ & $\begin{array}{l}\text { Isoflurane } \\
(n=114)\end{array}$ & $\begin{array}{l}\text { Sevoflurane } \\
(n=12 I)\end{array}$ & $\begin{array}{l}\text { Isoflurane } \\
(n=114)\end{array}$ \\
\hline Holter duration (hr) & $12.1 \pm 0.40$ & $12.5 \pm 0.41$ & $1.83 \pm 0.10$ & $1.90 \pm 0.10$ \\
\hline Myocardial ischaemia $(n)$ & $14(12 \%)$ & $15(13 \%)$ & $9(7 \%)$ & $13(11 \%)$ \\
\hline Ischaemic events ( $n$ ) & 31 & 30 & 21 & 27 \\
\hline Patient on a $\beta$-blocker (ratio) & $9: 14$ & $8: 15$ & $5: 9$ & $6: 13$ \\
\hline Duration of ischaemia (min) & $27.4 \pm 5.84$ & $20.0 \pm 5.64$ & $17.9 \pm 6.06$ & $17.3 \pm 5.05$ \\
\hline Severity of myocardial ischaemia $(\mathrm{mm} \cdot \mathrm{min})$ & - & - & $37.1 \pm 13.8$ & $28.1 \pm 9.5$ \\
\hline
\end{tabular}

No statistical difference between groups for any of the parameters. Values are mean \pm SEM.

TABLE VII Summary of myocardial infarction and incidence of adverse cardiac events

\begin{tabular}{lccc}
\hline & $\begin{array}{c}\text { Sevoflurane } \\
(n=140)\end{array}$ & $\begin{array}{c}\text { Isoflurane } \\
(n=133)\end{array}$ & $P$ value \\
\hline Myocardial infarction & & & \\
- CK-MB & $20(14.3 \%)$ & $14(10.5 \%)$ & NS \\
- Q wave 240 msec, $25 \%$ R wave & $10(7.2 \%)$ & $13(9.8 \%)$ & NS \\
- Both* & $3(2.2 \%)$ & $6(4.5 \%)$ & NS \\
- Either & $27(19.4 \%)$ & $21(15.8 \%)$ & NS \\
Other outcomes & 1 & 0 & NS \\
- Ventricle failure & 0 & 1 & NS \\
- Cardiac death & 1 & 3 & NS \\
- Noncardiac death & 1 & & \\
\hline
\end{tabular}

*Patient that met the following criteria were included: our elevated CK-MB isoenzyme (according to set criteria) and the development of new $Q$ waves ( $Z 40 \mathrm{msec}, 25 \% \mathrm{R}$ wave) on a 12-lead ECG.

ments, we may assume that sevoflurane has a similar dose-response curve to isoflurane.

Neither drug was associated with an increased incidence of intraoperative myocardial ischaemia, postoperative myocardial infarction, a postoperative cardiac or noncardiac death. In a nonrandomized study, Slogoff $e t$ al. ${ }^{19}$ reported a higher incidence of intraoperative myocardial ischaemia while our results are more in keeping with recent published results. ${ }^{20}$ The lower incidence of myocardial ischaemia found in this study may be explained by differences in the study design. In our study, the anaesthetic technique was standardized and, more importantly, strict criteria were applied for control and treatment of abnormal haemodynamic events. Neither isoflurane nor sevoflurane appeared to be associated with an increased incidence of myocardial ischaemia in this population with known severe CAD. It has been suggested that isoflurane may be associated with a higher incidence of myocardial ischaemia because of a coronary steal effect. ${ }^{21}$ However, in clinical practice, the importance of this effect remains controversial; it is not associated with a greater incidence of myocardial ischaemia detected by Holter monitoring even in large clinical studies. ${ }^{22,23}$ Other well-controlled investigations support the safety of isoflurane in high-risk patients with $\mathrm{CAD}$ when blood pressure and heart rate are maintained close to baseline levels. ${ }^{7,24,25}$ Using more sophisticated measurements of myocardial ischaemia, such as transoesophageal echocardiography or coronary sinus lactate metabolism, ${ }^{26}$ it is possible that a difference in the incidence of myocardial ischaemia existed between groups. However, such a difference would have been small and may not be clinically relevant. ${ }^{27}$ These sensitive measurement techniques are prohibitively expensive in the context of a large multicentre study, and may fail to detect a difference when tight control of haemodynamic variables is achieved ${ }^{28}$ such as was accomplished in this study.

Using our predefined criteria for CK-MB diagnosis of myocardial infarction, we found an incidence of $\mathrm{MI}$ (14.3\% Group S and $10.5 \%$ Group I, $P=$ NS), compared with the incidence of MI diagnosed on the 12-lead ECG (7.2\% for Group S and $9.8 \%$ for Group I, $P=\mathrm{NS}$ ). The presence of both criteria for perioperative MI showed that Group S had a $2.2 \%$ incidence while Group I had an incidence of $4.5 \%(P=\mathrm{NS})$. The incidence of adverse cardiac outcomes is also comparable with the published data for a low risk patient population. ${ }^{29,30}$

Since the pioneering work of Wynands et al. ${ }^{31}$ in 1967 , techniques of anaesthesia for patients with CAD have evolved because of a better understanding of the coronary physiology and the introduction of new anaesthetic agents. In recent years, there has been a renewed interest in the use of inhalational agents in patients undergoing $\mathrm{CABG}$ surgery. ${ }^{32}$ This interest may have been fostered by findings suggesting that inhalational agents are beneficial for protection of the ischaemic myocardium ${ }^{33-35}$ and by the resurgence of early tracheal extubation following CABG surgery. ${ }^{32}$ 


\section{Study limitations}

This study has several limitations. One of which pertained to the study population. Only the healthiest CAD patients were chosen for participation where the outcomes were expected to be good. Thus, differences between volatile anaesthetic agents were not expected to be great. Our results cannot be extended to patients with severe left ventricular function or with valvular disease. Would these results be any different if we had less healthy patients. remains to be proven. Sevoflurane will require to undergo further phase IV clinical trials in higher risk $\mathrm{CAD}$ and in valvular patients.

Secondly, the exposure of the patients to the volatile anaesthetics was restricted to the preCPB period. This is not necessarily in line with current cardiac anaesthetic practice for low risk patients where early extubation is planned: Further studies, in CAD patients, will have to address this issue of longer sevoflurane administration and likewise during CPB.

Thirdly, the dose of volatile anaesthetics among centres and patients' was variable; thus, one could not ascribe whether the inhalational agent was used as an adjuvant in some cases and as a primary anaesthetic in others. Overall; it appears that $0.30 \mathrm{MAC}$ was used for induction and approximately 0.60 MAC for maintenance. The morphine-benzodiazepine premedication; fentanyl-midazolam-vecuronium use during induction and a supplemental dose of feritanyl $\left(10 \mu \mathrm{g} \cdot \mathrm{kg}^{-1}\right)$ at sternotomy are responsible for the low concentration of volatile anaesthetic used. One could also argue that, in some patients receiving nearly $25 \mu \mathrm{g} \cdot \mathrm{kg}^{-1}$, fentanyl was the primary anaesthetic agent.

Lastly, this study had the power to determine a $15 \%$ reduction in myocardial ischaemia with an expected intraoperative incidence of $15 \%$. Our intraoperative incidence averaged only $10 \%$ thus we would have required more patients to show a difference if one had existed. Similarly, other cardiac outcome events, such as myocardial infarction, would require more than 2,000 patients to detect a difference. Thus, no difference was expected to be found in this study.

In conclusion, both inhalational anaesthetic agents appear to be safe and provide reasonable haemodynamic control in this low-risk patient population undergoing $\mathrm{CABG}$. Both groups of patients had a similar incidence of intraoperative myocardial ischaemia and postoperative morbidity and mortality. To be useful, newer inhalational anaesthetic agents must cause no or minimal cardiac depression, and must have no deleterious haemodynamic or coronary effects. The results of this study confirm that both sevoflurane and isoflurane, when used with fentanyl, - fulfil these requirements but further clinical investigations are required in patients with depressed left ventricular function.

\section{Acknowledgment}

The authors wish to acknowledge the excellent secretarial work of Mrs. Claire Bertrand-St-Hilaire.

\section{References}

1 Mangano DT, Browner WS, Hollenberg $M$, et al. Association of perioperative myocardial ischemia with cardiac morbidity and mortality in men undergoing noncardiac surgery. N Engl J Med 1990; 323: 1781-8.

2 Moffitt EA, Sethna DH. The coronary circulation and myocardial oxygenation in coronary artery disease: effects of anesthesia. Anesth Analg 1986; 65: 395-410.

3 Hoeft A, Sonntag H, Stephan H, Kettler D. The influence of anesthesia on myocardial oxygen utilization efficiency in patients undergoing coronary bypass surgery. Anesth Analg 1994; 78: 857-66.

4 Buffington CW, Romson JL, Levine A, Duttlinger NC, Huang $A H$. Isoflurane induces coronary steal in a canine model of chronic coronary occlusion. Anesthesiology 1987; 66: 280-92.

5 Slogoff S, Keats AS, Dear WE, et al. Steal-prone coronary anatomy and myocardial ischemia associated with four primary anesthetic agents in humans. Anesth Analg 1991; 72: 22-7.

6 Miller DR, Wellwood M, Teasdale SJ, et al. Effects of anaesthetic induction on myocardial function and metabolism: a comparison of fentanyl, sufentanil and alfentanil. Can J Anaesth 1988; 35: 219-33.

7 Thomson IR, Putnins $C L$. Adverse effects of pancuronium during high-dose fentanyl anesthesia for coronary artery bypass grafting. Anesthesiology 1985; 62: 708-13.

8 Helman JD, Leung JM, Bellows WH, et al. The risk of myocardial ischemia in patients receiving desflurane versus sufentanil anesthesia for coronary artery bypass graft surgery. Anesthesiology 1992; 77: 47-62.

9 Weiskopf RB, Moore MA, Eger EI II, et al. Rapid increase in desflurane concentration is associated with greater transient cardiovascular stimulation than with rapid increase in isoflurane concentration in humans. Anesthesiology 1994; 80: 1035-45.

10 Eger EI II. New inhaled anesthetics. Anesthesiology 1994; 80: 906-22.

11 Frink EJ Jr, Malan TP, Atlas M, Dominguez LM, DiNardo $J A, B r o w n B R J r$. Clinical comparison of sevoflurane and isoflurane in healthy patients. Anesth Analg 1992; 74: 241-5.

12 Frink EJ Jr, Malan TP Jr, Isner RJ, Brown EA, Morgan $S E$, Brown BR Jr. Renal concentrating function with prolonged sevoflurane or enflurane anesthesia in volunteers. Anesthesiology 1994; 80: 1019-25. 
13 Harkin CP, Pagel PS, Kersten JR, Hettrick DA, Warltier $D C$. Direct negative inotropic and lusitropic effects of sevoflurane. Anesthesiology 1994; 81: 156-67.

14 Bernard J-M, Wouters PF, Doursout M-F, Florence B, Chelly $J E$, Merin $R G$. Effects of sevoflurane and isoflurane on cardiac and coronary dynamics in chronically instrumented dogs. Anesthesiology 1990; 72: 659-62.

15 Nakamura K, Toda H, Hatano Y, Mori K. Comparison of the direct effects of sevoflurane, isoflurane and halothane on isolated canine coronary arteries. Can J Anaesth 1993; 40: 257-61.

16 Kersten JR, Brayer AP, Pagel PS, Tessmer JP, Warltier $D C$. Perfusion of ischemic myocardium during anesthesia with sevoflurane. Anesthesiology 1994; 81: 995-1004.

17 Larach DR, Schuler HG. Direct vasodilation by sevoflurane, isoflurane, and halothane alters coronary flow reserve in the isolated rat heart. Anesthesiology 1991; 75: 268-78.

18 Ramsay JG, DeLima LGR, Wynands JE, O'Connor JP, Ralley FE, Robbins $G R$. Pure opioid versus opioidvolatile anesthesia for coronary artery bypass graft surgery: a prospective, randomized, double-blind study. Anesth Analg 1994; 78: 867-75.

19 Slogoff S, Keats AS. Does perioperative myocardial ischemia lead to postoperative myocardial infarction? Anesthesiology 1985; 62: 107-14.

20 Mangano DT, Siliciano D, Hollenberg $M$, et al. Postoperative myocardial ischemia. Therapeutic trials using intensive analgesia following surgery. Anesthesiology 1992; 76: 342-53.

21 Priebe $H$-J. Isoflurane and coronary hemodynamics. Anesthesiology 1989; 71: 960-76.

22 Slogoff S, Keats AS. Randomized trial of primary anesthetic agents on outcome of coronary artery bypass operations. Anesthesiology 1989; 70: 179-88.

23 Tuman KJ, McCarthy RJ, Spiess BD, DaValle M, Dabir R, Ivankovich $A D$. Does choice of anesthetic agent significantly affect outcome after coronary artery surgery? Anesthesiology 1989; 70: 189-98.

24 Leung JM, Hollenberg $M$, O'Kelly BF, Kao A, Mangano $D T$, the SPI Research Group. Effects of steal-prone anatomy on intraoperative myocardial ischemia. J Am Coll Cardiol 1992; 20: 1205-12.

25 Pulley DD, Kirvassilis GV, Kelermenos $N$, et al. Regional and global myocardial circulatory and metabolic effects of isoflurane and halothane in patients with steal-prone coronary anatomy. Anesthesiology 1991; 75: 756-66.

26 Diana P, Tullock WC, Gorcsan J III, Ferson PF, Arvan S Myocardial ischemia: a comparison between isoflurane and enflurane in coronary artery bypass patients. Anesth Analg 1993; 77: 221-6.
27 Mangano DT. Anesthetics, coronary artery disease, and outcome: unresolved controversies (Editorial). Anesthesiology 1989; 70: 175-78.

28 Leung $J M$, Goehner $P, O^{\prime} K e l l y B F$, et al. Isoflurane anesthesia and myocardial ischemia: comparative risk versus sufentanil anesthesia in patients undergoing coronary artery bypass graft surgery. Anesthesiology 1991; 74: 838-47.

29 Higgins TL, Estafanous FG, Loop FD, Beck GJ, Blum JM, Paranandi $L$. Stratification of morbidity and mortality outcome by preoperative risk factors in coronary artery bypass patients. A clinical severity score. JAMA 1992; 267: 2344-8.

30 Jain $U$. Myocardial infarction during coronary artery bypass surgery. J Cardiothorac Vasc Anesth 1992; 6: 612-23.

31 Wynands JE, Sheridan CA, Kelkar $K$. Coronary artery disease and anaesthesia (experience in 120 patients for revascularization of the heart). Can Anaesth Soc J 1967; 14: 382-98.

32 Hall RI. Anaesthesia for coronary artery surgery - a plea for a goal-directed approach. Can J Anaesth 1993; 40: 1178-94.

33 Tarnow J, Markschies-Hornung A, Schulte-Sasse U. Isoflurane improves the tolerance to pacing-induced myocardial ischemia. Anesthesiology 1986; 64: 147-56.

34 Davis RF, Sidi A. Effect of isoflurane on the extent of myocardial necrosis and on systemic hemodynamics, regional myocardial blood flow, and regional myocardial metabolism in dogs after coronary artery occlusion. Anesth Analg 1989; 69: 575-86.

35 Warltier DC, Al-Wathiqui MH, Kampine JP, Schmeling $W T$. Recovery of contractile function of stunned myocardium in chronically instrumented dogs is enhanced by halothane or isoflurane. Anesthesiology 1988; 69: 552-65.

\section{Appendix}

\section{Participating institutions}

Dr. A. Al-Hasani

Groby Road Hospital

Groby Road

Department of Anaesthesia

Leicester

Leicestershire LE3 9QE

United Kingdom

Dr. Peter Conzen

Inst. für Anästhesiologie

Klinikum Großhadern

Marchioninistraße 15

Munich 7081377 Germany 
Thomas Ebert, MD, PhD

St. Luke's Medical Center

Department of Anesthesia

2900 W. Oklahoma Ave.

Milwaukee, WI 53215 USA

Prof. Daniel Enquérant

Bichat Hospital

Department of Anesthesiology

46 rue Henri-Huchard

75018 Paris France

Mark Ereth, MD

Mayo Clinic

Department of Anesthesia

St. Mary's Hospita', Facility

200 First Street SU

Rochester, MN 55905 USA

Roberta Hines, MD

Yale University School of Medicine

Department of Anesthesiology

P.O. Box 333, 333 Cedar St.

New Haven, CT 06510 USA

Lewis R. Hodgins, MD

Durham VA Medical Center

Department of Anesthesiology

508 Fulton St., Wing C4017

Durham, NC 27705 USA

Derek Horstemeyer, MD

Georgia Baptist Medical Center

Department of Anesthesia

300 Blvd. NE, Box 404

Atlanta, GA 30312 USA

W. Scott Jellish, MD, PhD

Loyola University Medical Center

Department of Anesthesiology

2160 South First Avenue

Maywood, IL 60153 USA

Lynette Mark, MD

Johns Hopkins University

Department of Anesthesiology

600 N. Wolfe St., Tower 711

Baltimore, MD 21287 USA
Alan Ross, MD

University of Iowa

Department of Anesthesia

6532 J.C.P., 200 Hawkins Drive

Iowa City, IA 52242 USA

Michael T. Salman, MD

University of Texas Medical School

Department of Anesthesiology

5323 Harry Hines Blvd.

Dallas, TX 75235 USA

Norman R. Searle, MD, CM

Montreal Heart Institute

Department of Anaesthesia

5000 Belanger Street

Montreal, Quebec, H1T 1C8 Canada

Raymond J. Martineau, MD

Montreal Heart Institute

Department of Anaesthesia

5000 Belanger Street

Montreal, Quebec, H1T 1C8 Canada 